\title{
Triangulating the Two Cultures Entanglement: The Sciences and the Humanities in the Public Sphere
}

\author{
Anton Kirchhofer and Anna Auguscik
}

\section{The Sciences, the Humanities, and the "gulf of mutual incomprehension"}

For quite a long time now, we have lived with the two cultures divide. A "gulf of mutual incomprehension", wrote C.P. Snow, is dividing "literary intellectuals" from scientists, and creating an inability to communicate, a mutual inability to understand and appreciate each other (3-4). Scholars are not quite in agreement about how long this has been going on but there is widespread consensus on the disadvantages of the situation, coupled with suggestions for how to overcome it or a resigned acceptance of its unwelcome persistence (Gould, Cordle, Waugh).

In exploring the range of perspectives open to the ScienceHumanities, it is worth considering to what extent this focus on the mutual perceptions and reinterpretations of the humanities and the sciences, and the disciplinary anxieties which may inform them, has itself a limiting effect on our analysis. If, half a century after Snow, the two cultures debate is still "an obligatory but uninspiring inclusion" (Sleigh 3) in scholarship on literature and science, it may be because this concentration on a two-way relationship fosters the tendency of the debate to lock itself into familiar channels.

Our purpose here is to guide the discussion about the relationship between the sciences and the humanities away from the question of their mutual perception in order to see how that relationship may look different once we shift the focus towards how the sciences and humanities are perceived from additional angles of observation. We aim for a reorientation that proceeds from a discussion of the attitudes of the public sphere to both the sciences and the humanities. We illustrate this by analysing novelistic representations of scientific concepts and practices, as well as the varied and sometimes controversial responses of general, literary and scientific readers to these. Our goal is not to undertake a redescription of the other discipline in terms of our own, but to make visible - and thereby available for public understanding and public discussion - the underlying structures of mediated communication about science.

\section{Triangulation: The Sciences, the Humanities, and their Observers}

The research which informs our essay has grown out of our ongoing work on the media presence of the contemporary Anglophone science novel. The project is part of the research group Fiction Meets Science and examines how scientific and literary reviewers respectively speak about science in fiction (Gaines et al.). The novels we study variously involve scientist characters, they are set at least partly in scientific institutions or laboratories, and they present emplotments of science by integrating scientific conceptions, problems or practices into the structures of their plots. With these science novels, contemporary fiction joins the spectrum of media engaged in the public observation of the sciences, employing media-specific, literary modes for the purpose of representing and evaluating the actions and conceptions of scientists. The fictional observation of science and scientists in turn becomes the object of observation, not only by the regular channels of literary reviewing, but also by the writers in science journals.

By integrating these various angles of public observation into the picture, we undertake a form of triangulation to guide the discussion about the relationship between the sciences and the humanities away from the question of their mutual perception. In 
choosing the metaphor of triangulation we are sensitive to the psychological currency of the term, but we have chosen the concept primarily on the strength of its original sense in trigonometry - a procedure to determine the distance and relative position of two points to each other by measuring the different angles in which they stand towards a third point. We apply an analogous procedure to the sciences and the humanities, using the respective angles of public observation as differentiating factors. Our goal is to make visible an entanglement which remains largely unproblematised once one takes a stance on either side, and to bring into view both the underlying structures of communicating about science and the multiple forms in which these communications happen.

In order to explore the potential of this practice of triangulating the sciences and humanities, we first consider, in the next section, the relative position of each towards the public sphere. As we shall see, the sciences and the humanities have historically evolved differences in the routine versions of their mutual relationship with the public sphere and public media, and we suggest that the contemporary novel is a site where such routines are disrupted.

\section{Recognizing Entanglements: Novels and the Public Observation of Science}

In a recent paper on "Scientists as Public Communicators", sociologist of science Hans Peter Peters revisited the "Gap between Science and Media". Summarising the findings of numerous studies, he finds that " $[\mathrm{m}]$ ost scientists assume a two-arena model with a gap between the arenas of internal scientific and public communication. They want to meet the public in the public arena, not in the arena of internal scientific communication." (14102) In relation to the public arena, Peters reports, "scientists agree that it is "essential to establish communication as a dialogue between two equal partners", but at the same time "they want to exclude the public from internal scientific communication", because "they feel restricted by their perception of the public's limited competence in dealing with science as well as by the scientific norm of separating internal scientific and public communication" (14108). As long as the distinction between the public and internal arenas is understood in terms of specialist expertise ("the public's limited competence"), the public can never join in the internal discussion among scientific experts on an equal footing; its angle on the issues will always remain imperfect however much it may aspire towards a more perfect insight into them.

This is not only manifested in the classical formats of science communication, but also in its more recent modes, such as those connected with the so-called narrative turn in science communication (Monteagudo; Dahlstrom) where the target groups are distinctly identified as non-expert audiences. Moreover, the public perception of the sciences is widely perceived as a problem in science and society. The designations given to the issue - from "Public Understanding of Science" to "Public Engagement with Science and Technology" - clearly place the public in a position of imperfect knowledge, which encourages them to aspire to knowledge they will never fully accomplish. By and large the public, too, seemingly accepts the role of the non-expert who may aspire towards an understanding of scientific issues which, however, they will never fully achieve or be admitted to.

The relationship between the humanities and the public tends to be cast in different terms, even if, in reference to expertise and specialised technical vocabulary, the two arena model also applies to the relationship between the public and the humanities. But, while there is "science communication" on the one hand, no one speaks of "humanities communication" on the other. Instead, the emphasis is on 
different forms of debate - public debate, academic debate - which host a plurality of positions in non-egalitarian relationships towards each other, but with little readiness on the part of the public debate to defer to academic debate. The reviewing of literature is a case in point: the public media have their own formats and set of questions in review articles and other coverage of literary fiction; and they have their own marketing and fan-based ways of discussing genre fiction. In neither of these cases will the public wait for scholarly analysis of their judgments or appeal to academic literary studies for a better understanding of them. When academics are invited to contribute reviews and other articles on contemporary literature, they still adhere to the formats of public discussion, rather than bringing the standards of their disciplines to bear.

Instead of an idealised attitude that aspires to an understanding which must by necessity remain imperfect, among the humanities and the public there is an equally idealised sense of a shared pluralism. This is based on the recognition that there are competing viewpoints and alternative concerns or priorities. While there is a familiar notion that one of the functions of the humanities is to contribute critical angles to a pluralistic public debate (Marquard; Gethmann et al.; Honneth), there is an even wider public expectation that science provides explanations for existing phenomena and developments, as well as solutions for problems.

Reviews of contemporary science novels in the scientific media, however, suggest that the novel may be a site where these different perspectives become entangled. Science novels have been discussed both as science communication leading audiences towards aspiring to a better understanding of scientific concepts and also as part of the social debate about science (Goldman). However, the responses which many of these novels generate in scientific publications show that novels may be accorded a privilege which is particularly striking when it is viewed against the background of the established separation of the two arenas of communication on science.

Scientist reviewers may gauge the quality of a novel based on its skill in accurately representing scientific concepts (e.g. Rose). It even appears that in commissioning review articles on novels about science, science journal editors may specifically require their reviewers to do just this (Allen, "Plotting"). Scientist reviewers may also resolve to employ a suitable novel in their teaching, or conversely warn against the misconceptions about science which might be conveyed or reinforced by a novel. Nevertheless, their responses to representations of science and scientists in fiction often go beyond assessing the quality of a novel as science communication with non-expert audiences.

Effectively, scientist reviewers are more concerned with recognition than with science communication in a novel. Their attention is focused on the extent to which they recognise their world in the novel. This manifests itself in questions such as these: does the novel provide an accurate representation of the scientific concepts, settings, and practices which it describes or employs? Is the portrayal of scientists realistic? Is it flattering even? And not least, is the novel realistic in its portrayal of science in its political and economic contexts and its difficult relationship with the media, public sphere, and with non-expert audiences? Scientist reviewers are gratified by portrayals that adequately match their own perceptions of how they are seen by the public (Rohn), and they disapprove of what they perceive as misrepresentations (Burley). This does not imply that scientists invariably look for idealised, affirmative representations of their situations and activities. They emphatically welcome realistic descriptions of the difficult and conflicted social and economic frameworks within which scientists often operate (Weber; Mattoni). 
There is a complementary form of recognition, which consists in the hypothetical admission of the fictional narrative to the internal arena of communication among scientists. This happens specifically when a novel makes reference to technical or conceptual developments that extrapolate from the existing state of knowledge. Narratives may then be credited with potentially anticipating developments which will be realised in science in the future. In these cases, fiction figures as a site of scientific speculation. Scientist readers and reviewers will bring their expertise to bear on the concepts and scenarios presented in novelistic form, whether as science fiction, as science in other types of genre fiction, or as literary fiction.

What this brief survey demonstrates is that scientist reviewers may often accord a position beyond the confines of science communication to fictional science narratives. The first type of concern we identified above - the accurate representation of scientific concepts - can still be aligned with the goal of increasing the readers' scientific literacy, a communication of scientific information aimed at a public aspiring to approach an understanding which it cannot fully reach, on account of what Peters described as "the public's limited competence" (14108). However, the two additional perspectives - on the public's and the scientists' perception of the social, cultural and economic conditions and effects of practicing science, as well as on the relationship in which given concepts and scenarios of fictional science might stand towards actual science are aligned with the existence of alternative viewpoints, in the first case concerning science and scientists in the public sphere, and in the second case, concerning a plurality of viewpoints in the internal arena of scientific discussion.

The exceptional and unpredictable occurrence of these review articles in science journals has the potential to stimulate ad hoc, yet iterable and even lasting reflection, discussion and engagement. They have the potential to mobilise both the internal and the public arenas of communication about and among science and scientists. An analysis of the ensuing selective entanglements between these two arenas will allow us to describe the unique exchanges around science which these various novels spark off. It can provide us with a clearer vision of the underlying structures which shape the modes of communication about science in our societies. Within the cultural conversation about science and its relation to the public and the humanities, such an analysis can open up a perception that has not yet become widely acknowledged in any of the settings where science is discussed. It is, therefore, a valuable new arena where the ScienceHumanities might feasibly find purchase.

\section{Solar's Euphoric Entanglements}

Among many recent science novels, there is one which stands out with respect to the quantity and quality of positive attention that it received from scientist reviewers. As a rule, individual reviews tend to privilege one or another of the aspects in the spectrum outlined above, but Ian McEwan's Solar triggered all of these aspects. The range and detail of attention in the reception of Solar is exceptional: early and repeated notices appeared not only in Nature and the Nature group but also in other science journals (Hooper; Mitchison; Griggs in the New Scientist). In April 2010, within a month of the novel's publication, there were two review articles in the Nature group. Hans von Storch, a leading climatologist at the Helmholtz Centre Geesthacht, appreciates the novel as a sophisticated invitation to engage with social constructions of climate change, specifically praising its rejection of simplistic approaches to the subject - either from activists or so-called sceptics (1283). According to David Gevaux, then an editor for Nature Communications, who reviewed the novel for Nature Physics, "the book brings into focus a number of issues that should be pertinent to all modern, professional 
scientists" (236). Gevaux hails McEwan as a "truly gifted external reviewer" of the scientific and institutional practice of physics, and values the novel as a book not directly about physics, but about the range of different perceptions of physics in society (236). Gevaux also singles out McEwan for the authenticity of his scientific language and use of scientific concepts, and speculates, for instance, about the research regarding "the possible role of quantum mechanics in plant photosynthesis" that McEwan might have used in devising his protagonist's fictional discoveries in the field of renewable energies (236). Two subsequent pieces on Solar revert to the scientific potential inherent in the novel's fictional science. Philip Ball contributes an article on Solar to Nature Materials, in which he places the novel's fictional description of "photocatalytic water splitting" in the context of actual cutting-edge research on solar energy generation ("Material Witness" 614). In the following year, Ball contributes a substantial survey of even newer research on the potential future uses of quantum photosynthesis as a "key to quantum computing and high efficiency solar cells", which still takes its cue from the fictional science expounded in McEwan's novel ("A Novel Idea" 274).

As these examples show, scientist reviewers of Solar welcome the novel as a rare opportunity to forge a viable connection between their internal arena and the public arena of communicating about science, while they remain largely unconcerned with questions of science communication in the sense of increasing the level of scientific informedness in non-expert readers. There are three complementary forms in which Solar is credited with this ability. To begin with, reviewers widely embrace the portrayal of science and scientists as discerning, differentiated and full of insight, in spite of the deeply unflattering representation of its protagonist Michael Beard. Next, they find the novel sensitive and stimulating in its representation of the relationship between science and society. Finally, as the discussion of the various aspects of renewable energy demonstrate, they are even prepared to consider whether McEwan may have made a valid and interesting contribution to current and evolving perspectives for scientific research.

This differentiated and sustained positive reception stands out especially in comparison with the general reception of Solar. Among literary reviewers the novel was met with mixed reactions. Along with praise, there was a good deal of puzzlement, dismissal and outright lack of understanding, occasioned mostly by McEwan's choice of a deeply unappealing, excessively self-indulgent and morally compromised protagonist, and by this character's more than questionable views and actions which drive a good deal of the plot (Cowley; Urquhart).

Viewed against the assumption of a public aspiring to overcome the imperfection of its scientific competence, Solar might be read as an author's nearly perfect aspiration. However, an analysis of scientists' various responses, in comparison to those of literary reviewers, reveals a somewhat different picture: Solar depicts science and scientists in ways that scientist writers, and writers in scientific journals, recognise. This recognition is not limited to the aspect of accurate representation of scientific concepts and practices, but extends to scientists' views on the public perception of science and of issues of science and society, as well as to a potential incorporation of elements of the novel into the internal scientific debate. At the same time, the diverse viewpoints of literary reviewers in public media tend not to recognise that same fictional depiction of science and scientists that scientists recognise. This may simply be an effect of the reviewers' established focus on character in literary fiction to which McEwan's Beard presents a hard challenge. However, it might be connected more specifically to the persistence of societal stereotype of the scientists' role - for 
example, moral integrity and the idea that scientists are working for the good of society - to which the novel's protagonist emphatically does not correspond.

\section{State of Fear's Disturbing Entanglements}

Despite its unappealing protagonist, Solar was greeted with enthusiasm by scientists. The response of the scientific community to Michael Crichton's State of Fear (2004) offers a different picture. This novel affords very little of what scientist reviewers often find praiseworthy in science novels. As a result, it received a similar quantity though very different type of attention from the scientific community.

Science and scientist characters in State of Fear are for the most part the dupes or unwitting tools of the evil machinations of lawyers and environmental activists except for the mysterious scientist Kenner, a Harvard professor and secret agent. In the novel, he manages to thwart most of the conspiracies and give lectures about the scientific evidence against anthropogenic climate change while he is guiding the youthful heroes and heroines through spectacular and mind-boggling dangers and adventures. There is little discussion in the novel of scientific concepts, issues, characters and settings. Instead of an invitation to explore the complexities of science and society, there is a denial of scientific autonomy in favour of a conspiracy theory according to which a vast "politico-legal-media complex" dominates and predetermines all the knowledge that science can offer the public (456).

As a consequence, Michael Crichton's State of Fear has the dubious distinction of figuring, among the contributors to Nature, as the epitome of a seriously mishandled communication about science in the public arena. The editorial to a special issue on climate change in November 2005 feels compelled to refer to State of Fear as a "pseudoscientific novel" ("Heavy Weather" 258). Even in glossing responses to the "sad news" of the author's death, Nature suggests that, in State of Fear, Crichton presented "climate change as a fraud perpetuated by activists and scientists," and that he could have limited the political damage of his book by reminding right wing climate sceptics that it was "just a novel," but refused to do so ("From the Blogosphere" xiii). In Hans von Storch's review of Solar, Crichton's novel still figures as "a static stage on which wooden characters declare some preconceived truth" (1283).

The immediate responses in Nature show that the publication of State of Fear created quite a disturbance. A series of responses in Nature all circle around the ways in which State of Fear refuses to accept the "gap" and the established role distribution between the internal and public spheres of communication on science. Its thriller plot is built on discrediting the internal arena of scientific communication as compromised by financial and political interests. Instead of accepting the scientific consensus, the novel offers an alternative and competing account of climate history and current developments. The author positions his novel as a public voice engaging directly with the scientific consensus, and documenting the scientific evidence on which it draws (albeit in a jumbled collection of temperature graphs and bibliographic references, all apparently sufficient to prove that there is no anthropogenic climate change).

Scientists respond to this challenge in different ways, with various and potentially contradictory strategies. These are all contingent on the significance of the gap between the two arenas of public and internal communication, but they relate to this with contrasting trajectories. As a first strategy, we may identify a reassertion of the proper distance between the internal and the public arenas. In the earliest response in Nature, Philip Ball reminds Crichton that, as a member of the public, his proper role would be not to try and mix himself up with the internal discussions among scientists, but to seek to understand their outcomes to the best of his abilities. The fact that 
Crichton did not simply accept "the scientists' conclusions" and "wanted to make up his own mind" is not dismissed out of hand: it is "surely commendable that Crichton went and looked at the scientific data for himself," says the reviewer (Ball, "Brought to Book"). All the same, he goes on to conclude that "Michael Crichton should accept that scientists know more about climate change than he does" (Ball, "Brought to Book"). This is clearly a demand that the public observer of science return to the role of aspiring to the knowledge which is established by scientists in their internal arena of communication.

A second, more pointed form of this insistence on the integrity of the internal arena of scientific communication consists in re-activating two cultures clichés and science wars rhetoric. Nature's earliest response to the novel also reverts to a polarising rhetoric familiar from the two cultures debates and the science wars, when it calls on scientific readers to "resist [...] a culture (common in literary circles) that regards scientific facts as a matter of personal taste. Some non-scientists consider themselves as free to disagree with the second law of thermodynamics as they are to dispute Derrida's literary theory or the artistic value of the Surrealists." (Ball, "Brought to Book") The novelist is here not treated as a public observer, but as an exponent of the postmodern, relativist, social constructivist view supposed to be characteristic of the humanities. Crichton's novel is identified as the latest hostile takeover bid within a two cultures confrontation locked into unalterable and irresolvable conflict.

Other scientist responses point in an opposite direction. A third strategy consists in taking the scientific discussion into the public arena. A "group of respected climate scientists who are determined to tackle what they see as poor media coverage of their field" decided within a week of the book's publication to post "a detailed critique of its contents $[\ldots]$ on a new website targeted at journalists and the public" (Giles 937). The site, realclimate.org, is immediately discussed in Nature. As it turns out, the idea of accepting Crichton's challenge by bringing the internal scientific debate into the public arena faces "a dilemma" (Giles 937). For one thing, the established rules of the internal arena have to be partly suspended, as conventional peer review is incompatible with the site's need for rapid response. The site therefore runs the risk of underrepresenting the critical discussion and process that happens within science, and of "presenting a "party line' on climate science that could be seen as attempting to limit debate" and as "blur[ring] the line between science and advocacy" (Giles 937). For the same reasons, "the project may struggle to accommodate respected climate scientists who dissent from aspects of mainstream thinking on climate change" (Giles 937). The difficulty here concerns the insufficient public insight into the inherent pluralism of debate in the internal arena, one which cannot be adequately projected into the public arena. The risk associated with this strategy, then, is that when scientists take their scientific discussion into the public arena, it has to play by the rules of the public arena, rather than by its own.

A fourth distinctive move may be paraphrased as deploring the inability of the public media to ask critical questions when faced with what looks like scientific claims to authority: "Part of the problem is that because Crichton has written a novel and not a scientific treatise, he has been granted the luxury of airing these views on arts programmes, where there is no one to challenge him" one respondent points out, adding: "'You are nothing if not scrupulous in your research,' one BBC presenter (who grills politicians ruthlessly) averred admiringly" (Ball, "Brought to Book"). Another problem of the public arena, as it turns out, is its undeveloped ability not only to criticise scientific claims, but to understand how scientific claims are subjected to criticism 
before they become accepted. Several writers subsequently return to this point (Allen, "A Novel View"; Smith).

As in the reception of Solar, there is a striking contrast between the responses in scientific publications and in general review media. The Guardian, for example, does not feel the need to do a proper review of the novel, though it offers a sequence of ridiculing summaries (Barkham; Lewin; also Crace). At the same time, it persistently records the public effect which State of Fear has elsewhere, responding to the positive comments on the book in The Times ("Critical Eye") and The Telegraph (Monbiot), reporting on the heavy criticism levelled by eminent scientists against the book (McKie, "How We Put" and "Loony Jibe"), and expressing "something of a shock" when it transpired that Crichton has been invited as a climate science expert, on the strength of his book, to testify before a US senate hearing (Wilson). Instead of a direct engagement with the book, then, there is reluctant and dismissive attention, which invariably is triggered by the fact that State of Fear attracted significant attention elsewhere.

Several readings seek to locate Michael Crichton's State of Fear on the discursive map of a public supposed to be aspiring towards overcoming the imperfection of its scientific knowledge ("the public's limited competence"). Scientists appear to read the novel as a defiance, a rejection of the aspiring role, an arrogation of a position of authority normally reserved for scientists. The picture of public responses to the novel shows that it is widely read as articulating a fairly extreme position in a pluralistic spectrum of public voices in the climate change debate - but that it is also sometimes misrecognised as science, i.e. as possessing scientific authority (for example, the Guardian's "shock" and Ball's frustration with the BBC interview with Crichton, mentioned above).

This aspect of the public's misrecognition emerges as a central feature from our analysis of the reception of both novels. In both cases, misrecognition is, at best, indirectly a question of the public's limited scientific competence. It is rather a failure to recognise the scientists' perspective - how scientists see not only their respective disciplines and specialisms but also the public's conceptions and expectations of science - and specifically there is an insufficient public understanding of what we have called the inherent pluralism of debate in the internal arena. It is not the limited competence in a particular field of research (for example, in quantum physics, or genetics, or climate science) which distinguishes scientists from the general public. This limited competence would also be shared by many scientists once they are beyond their particular field or discipline. What distinguishes these two perspectives is rather a specific lack of insight, and a lack of recognition of the internal pluralism of science.

\section{Conclusions}

The idea that we need a greater recognition of the internal pluralism of science might have wider implications for research programmes in the ScienceHumanities. What is involved is not only the idea that scientific debate, too, is pluralistic, but also that the pluralism of debate in the internal arena is not the same type of pluralism as the pluralism of opinion or pluralism of positions that is characteristic of the public arena. Moreover, scientists are clearly aware of the type of pluralism that is essential to scientific research, but there may also be factors that make them complicit in downplaying or, at least, imperfectly promoting a sense of it. There is a payoff here: the prestige of science as a provider of the solutions and explanations which society requires. There is also a cost which science incurs for the low transparency of its own internal pluralism: this cost includes an occasional or systemic public misrecognition of science. 
Viewed side by side, these two novels and the various responses to them can help, then, to clarify our conception of the evolving relationship between the sciences and the public, as well as between the sciences and the humanities. Both the disruption caused by State of Fear and the celebration of viable forms of dialogue and exchange occasioned by Solar bear testimony to the high significance attached, from a scientist's perspective, to the distinction between public and internal communication.

Both novels show how the public and internal arenas become entangled with each other. However, in neither case does this lead to the creation of a shared arena. State of Fear not only prompts conflicting impulses among the scientists that respond to it, but also manages to draw a significant number of respected scientists into the public arena, although it does not lead to a concerted reflection of the different constitutive features of each type of pluralistic arena. Neither does Solar manage to create a shared arena. As in the case of Crichton's novel, Solar does not bring about a dialogue involving scientists and public voices in an exchange about "climate change as a social construct" (von Storch) and the relationship between the social construct on the one hand, and the scientific study and state of scientific research on it on the other hand. What von Storch points to here is the fact that climate change in science is a different object than climate change in the public discussion. That climate change is constructed differently in the different arenas of communication, we may now suggest, is also due to the fact that in each sphere it corresponds to a different type of pluralism - it is tied to different ideas, concepts and practices, entails different consequences and actions, and is developed as a notion and shared concept through different procedures. To note this difference is not to advocate for the sort of cultural relativism so often invoked as a bogeyman in the exchanges to which we referred at the opening of this essay. It is, to use von Storch's phrase, to describe real differences with real effects in the real world.

For this reason, the significance of analysing how novels can have the effect of entangling the internal and public arenas of communication about science goes beyond their assumed potential to be a more powerful form science communication. What it permits us to perceive more clearly is the underlying structures of communication about science. Specifically, it reveals the extent to which we do not yet have an established public understanding of these structures.

Science novels have a unique potential for positioning themselves and creating situations of dialogue beyond the received settings. Given the discursive position of literary fiction, the articulation of this potential must by necessity remain isolated and incidental. Nevertheless, our analysis has made it clear that there is insufficient public understanding of the internal pluralism of science. It may highlight also a more general insufficiency in understanding the different forms of innovation and critique which are characteristic of the sciences, the humanities, and perhaps the public, too. In the context of the ScienceHumanities, this insight may be useful in defining where the contribution of the humanities and their distinctive capacity for critical and historical analysis might lie. Instead of attempting a competing re-description of the sciences (a covert or overt takeover bid), such work can aim to replace the idea of a generalised "gulf of mutual misunderstanding" between the sciences and the humanities, as well as between the sciences and the public, with an investigation of concrete conditions, and the identification of concrete and remediable deficits.

\section{Acknowledgements}

The authors are grateful to the Volkswagen Foundation for its generous support of their work on this essay as part of the Fiction Meets Science (FMS) project. 


\section{Works Cited}

Allen, Myles. "A Novel View of Global Warming." Review of State of Fear, by Michael Crichton. Nature, vol. 433, no. 7023, 20 Jan. 2005, p. 198.

---. "Plotting the Course of Climate Change." Review of Forty Signs of Rain, by Kim Stanley Robinson. Nature, vol. 428, no. 6986, 29 Apr. 2004, p. 894.

Ball, Philip. “A Novel Idea: Quantum Fact Meets Fiction.” Review of Solar, by Ian McEwan. Nature, vol. 474, no. 7350, 16 Jun. 2011, p. 274.

---. "Brought to Book." Nature.com, 20 Dec. 2004, www.nature.com/news/ 2004/041220/full/news041220-4.html. Accessed 18 Dec. 2017.

---. "Material Witness: Quantum Leaves in Fact and Fiction." Review of Solar, by Ian McEwan. Nature Materials, vol. 9, no. 8, Aug. 2010, p. 614.

Barkham, Patrick. "Jurassic Park Author Pours Cold Water on Global Warming." The Guardian, 11 Dec. 2004, www.theguardian.com/uk/2004/dec/11/ environment.world. Accessed 18 Dec. 2017.

Burley, Justin. "Exactly the Same But Different." Review of The Secret, by Eva Hoffman. Nature, vol. 417, no. 6886, 16 May 2002, pp. 224-225.

Cordle, Daniel. Postmodern Postures: Literature, Science, and the Two Cultures Debate. Ashgate, 1999.

Cowley, Jason. "Ian McEwan excels at climate science but his one-dimensional protagonist makes you shudder." Review of Solar, by Ian McEwan. The Guardian, 14 Mar. 2010, www.theguardian.com/books/2010/mar/14/solar-ianmcewan. Accessed 18 Dec. 2017.

Crace, John. "Digested Read: State of Fear by Michael Crichton." The Guardian, 9 Mar. 2010, www.theguardian.com/theguardian/2004/dec/20/ digestedread.theeditorpressreview7. Accessed 18 Dec. 2017.

Crichton, Michael. State of Fear. 2004. HarperCollins, 2013.

"Critical Eye: Unreal Scenarios." The Guardian, 8 Jan. 2005, www.theguardian.com/books/2005/jan/08/featuresreviews.guardianreview 10 .

Accessed 8 Jul. 2014.

Dahlstrom, Michael F. "Using Narratives and Storytelling to Communicate Science with Nonexpert Audiences." Proceedings of the National Academy of Science, vol. 111, no. 4, 2014, pp. 13614-20.

"From the Blogosphere." Nature, vol. 456, no. 7220, 20 Nov. 2008, p. xiii.

Gaines, Susan, et al. "Fiction Meets Science: Background and Concept." Fiction Meets Science, Aug. 2013, www.fictionmeetsscience.org/ccm/content/resources/ concept---working-papers/concept-paper-1/. Accessed 18 Dec. 2017.

Gethmann, Carl F., et al. Manifest Geisteswissenschaften. BBAW, 2005.

Gevaux, David. "Physicists in the glare of the Sun." Review of Solar, by Ian McEwan. Nature Physics, vol. 6, no. 4, Apr. 2010, pp. 236-237.

Giles, Jim. "Climatologists Get Real over Global Warming." Nature, vol. 432, no. 7070, 23 Dec. 2004, p. 937.

Goldman, Michael A. "Evolution Rising from the Grave." Review of Darwin's Radio, by Greg Bear. Nature, vol. 404, no. 6773, 2 Mar. 2000, pp. 15-16.

Gould, Stephen Jay. The Hedgehog, the Fox and the Magister's Pox: Mending the Gap between Literature and Science. Harmony, 2003.

Griggs, Jessica. "Ian McEwan: Mr Sunshine.” New Scientist, 30 Mar. 2010, pp. 24-25.

“Heavy Weather.” Editorial. Nature, vol. 438, no. 7066, 17 Nov. 2005, pp. 257-258. 
Honneth, Axel. "Denaturierungen der Lebenswelt. Vom dreifachen Nutzen der Geisteswissenschaften." Texte zur Theorie der Geisteswissenschaften, edited by Athena Panteos and Tim Rojek, Reclam, 2016, pp. 283-315.

Hooper, Rowan. "The Great Global Warming Satire." Review of Solar, by Ian McEwan. New Scientist, 8 Mar. 2010, www.newscientist.com/blogs/ culturelab/2010/03/ian-mcewan-solar.html. Accessed 18 Dec. 2017.

Lewin, Matthew. "Darkness and Might: State of Fear." The Guardian, 29 Jan. 2005, www.theguardian.com/books/2005/jan/29/featuresreviews.guardianreview18. Accessed 18 Dec. 2017.

Marquard, Odo. "Über die Unvermeidlichkeit der Geisteswissenschaften." Apologie des Zufälligen. Reclam, 1986, pp. 98-116.

Mattoni, R. "Flight Behavior by Barbara Kingsolver, 2012." The Journal of Research on the Lepidoptera, vol. 46, 1 May 2013, p. 23.

McEwan, Ian. Solar. Vintage, 2010.

McKie, Robin. “'Loony' Jibe at US Policy over Climate.” The Observer, 27 Nov. 2005, www.theguardian.com/science/2005/nov/27/research.highereducation. Accessed 18 Dec. 2017.

---. "How We Put the Heat on Nature." The Observer, 30 Jan. 2005, www.theguardian.com/science/2005/jan/30/observerfocus.environment. Accessed 8 Jul. 2014.

Mitchison, Graeme. "Imagining a Universe for Ian McEwan." New Scientist, 31 Mar. 2010, www.newscientist.com/blogs/culturelab/2010/03/imagining-a-universefor-ian-mcewan.php. Accessed 18 Dec. 2017.

Monbiot, George. "This is a dazzling debunking of climate change science. It is also wildly wrong." The Guardian, 14 Nov. 2006, www.theguardian.com/commentisfree/2006/nov/14/science.comment.

Accessed 18 Dec. 2017.

Monteagudo, José González. "Jerome Bruner and the Challenges of the Narrative Turn: Then and Now." Narrative Inquiry, vol. 21, no. 2, 2011, pp. 295-302.

Peters, Hans Peter. "Gap Between Science and Media Revisited: Scientists as Public Communicators." PNAS, vol. 110, suppl. 3, 20 Aug. 2013, pp. 14102-14109.

Rohn, Jennifer. "Turning to Fraud." Review of Intuition, by Allegra Goodman. Nature, vol. 440, no. 7087, 20 Apr. 2006, pp. 996-997.

Rose, Steve. "Affairs of the Mind." Review of Thinks ..., by David Lodge. Nature, vol. 411, no. 6835, 17 May 2001, pp. 241-242.

Sleigh, Charlotte. Literature and Science. Palgrave Macmillan, 2010.

Smith, Margaret E. "Seeds of discord" Nature, vol. 434, no. 7036, 21 Apr. 2005, pp. 957-958.

Snow, C.P. The Two Cultures and the Scientific Revolution. Cambridge UP, 1959.

Urquhart, James. "Solar, by Ian McEwan." The Independent, 10 Mar. 2010, www.independent.co.uk/arts-entertainment/books/reviews/solar-by-ianmcewan-5527479.html. Accessed 18 Dec. 2014.

Von Storch, Hans. "Under the Skin of Climate Change." Review of Solar, by Ian McEwan. Nature, vol. 464, no. 7293, 29 Apr. 2010, p. 1283.

Waugh, Patricia. "Revising the Two Cultures Debate: Science, Literature, and Value." The Arts and Sciences of Criticism, edited by David Fuller and Patricia Waugh. Oxford UP, 1999. 33-59.

Weber, D. C. "Entomology in Recent Fiction: Flight Behavior." Review of Flight Behavior, by Barbara Kingsolver. American Entomologist, vol. 59, no. 2, 2013, p. 123. 
Wilson, Jamie. "Novel Take on Global Warming." The Guardian, 29 Sept. 2005, www.theguardian.com/environment/2005/sep/29/comment.bookscomment. Accessed 18 Dec. 2017. 